\title{
ACERCAMIENTO A LA PROBLEMÁTICA ECLESIÁSTICA DE ZACATECAS A PARTIR DE UN EXPEDIENTE DE PARROQUIAS (1831-1832)
}

\author{
POR \\ RoSALINA Ríos ZÚÑIGA \\ Universidad Nacional Autónoma de México
}

\section{RESUMEN}

El artículo analiza un expediente de parroquias elaborado con los informes enviados a las autoridades civiles de Zacatecas por un buen número de curas párrocos, en los que informaban sobre la situación del cobro de las obvenciones parroquiales en una buena parte del estado hacia 1831. El objetivo es conocer cómo estaban resolviéndose las cuestiones entre Estado- Iglesia en la entidad y qué tipo de problemas enfrentaba ésta, en particular a partir de los ámbitos más bajos de su estructura, como eran las parroquias y el cobro a los feligreses por los servicios que les prestaban los curas. Con ese fin, describe a grandes rasgos los aspectos conflictivos entre autoridades civiles y eclesiásticas, en particular desde la política llevada a cabo por el gobernador Francisco García Salinas y su grupo; enseguida se pone en contexto el documento, señalando tanto sus limitaciones como sus posibilidades.

PALABRAS CLAVE: Relaciones Estado-Iglesia, Zacatecas, parroquias, siglo XIX, obvenciones parroquiales.

\section{APPROXIMATION TO ZACATECAS'S ECCLESIASTIC PROBLEMATICS FROM A PROCESS OF PARISHES (1831-1832)}

\begin{abstract}
This essay explores the case of some parishes and parishioners in Zacatecas at the beginning of the $1830 \mathrm{~s}$. Based upon a series of reports made by priest, that informed on the status of the collection of parochial stipends, obvenciones in much of the state and the population to 1831 , it allows to know how the issues
\end{abstract}


had been resolving between State-Church in Zacatecas. Especially, focusing in lower levels of the ecclesiastical structure, as parishes and the charge for services delivered to parishioners, it outlines the conflicting issues between civil and ecclesiastical authorities, particularly since the policy carried out by Governor Francia García Salinas and his group; immediately analyzes different angles of the parochial reports, and points out both its limitations and potential.

KEY WORDS: parishes, parochial obvenciones, Zacatecas, State-Church relations, Nineteenth Century

Recibido/Received 15/03/2011

Aceptado/Accepted 30/04/2011

\section{INTRODUCCIÓN}

En junio de 1831, el congreso de Zacatecas pidió a los curas párrocos de la entidad que informaran sobre los ingresos que obtenían por cuenta de las obvenciones parroquiales ${ }^{1}$ que, como sabemos, eran los derechos que pagaban los feligreses por los diversos servicios de culto que les prestaban los curas localmente y que se pagaban desde tiempos novohispanos. Así, después de tener listos sus informes, un buen número de eclesiásticos -un total de 17-, enviaron sus respectivos documentos a las autoridades competentes, esto es a la Mitra de Guadalajara y al gobierno zacatecano.

La petición formaba parte, al parecer, de la serie de medidas que en esos años había echado a andar el gobierno encabezado por Francisco García Salinas con el fin de avanzar en la consolidación de las instituciones gubernamentales en la entidad. Y, sin duda, la cuestión eclesiástica era una de las más importantes, pues, como es sabido, a raíz de la independencia continuó la fuerte lucha de parte de las autoridades civiles orientada a lograr su predominio sobre la esfera eclesiástica, que se había iniciado desde el siglo XVIII con las reformas borbónicas. Zacatecas fue uno de los estados más radicales en el asunto.

De hecho, durante los años anteriores a 1831, los políticos locales habían mantenido una postura orientada a hacer valer el predominio del poder civil sobre el eclesiástico, incluso la tendencia provenía de parte de religiosos, participantes en la política, como lo demuestra la elocuente participación del diputado

\footnotetext{
${ }^{1}$ Informe de los curas en el estado de Zacatecas, sobre extensión de sus parroquias, número de habitantes de que éstas se componen y producto de sus emolumentos. 58 ff. Fondo LXXVI-2 1831-1832. Competencia de Curatos. Procedencia diversa. Centro de Estudios de Historia de México del grupo Carso. El término parroquia designa la demarcación territorial encargada a un cura párroco, mientras que curato se identifica más con la cabecera sede (física o material), en otros términos, sería la fábrica material, la iglesia. En algunas ocasiones pueden utilizarse como sinónimos, y en caso necesario así lo haremos en el presente trabajo.
}

Hispania Sacra, LXIII

128, julio-diciembre 2011, 653-679, ISSN: 0018-215-X 
por Tlaltenango y eclesiástico zacatecano, José Guadalupe Gómez Huerta, quien señalaba en 1827 la necesidad de que la nación ejerciera el Patronato. ${ }^{2}$

Sin embargo, la situación era ambigua, o al menos así lo parece, pues al mismo tiempo, conscientes de la importancia del poder religioso, las autoridades civiles locales manifestaron en algún momento su interés en la erección de un obispado en la entidad, puesto que, hasta entonces, el territorio de la provincia de Zacatecas quedaba bajo la égida de dos jurisdicciones eclesiásticas: por un lado, dos partidos ${ }^{3}$ de la zona norte pertenecían a la diócesis de Durango; por el otro, la mayor parte de la demarcación hacia el sur lo era de la de Guadalajara. Otras acciones políticas en la entidad marcarían la tendencia hacia el arreglo de la cuestión eclesiástica en el estado. En suma, la petición de informes a los curas párrocos se insertaba en el arreglo de toda una problemática en torno a las relaciones entre el Estado y la Iglesia, que tenían que encontrar, en el corto plazo, vías de solución.

Esa historia nos es desconocida en gran parte, pues pese a estar bastante cubierta la historia política, económica y social del estado para esa época, ${ }^{4}$ puede decirse que no existe hasta el momento en la historiografía sobre dicha entidad una obra que de manera clara y directa aborde la problemática entre el Estado y la Iglesia después de la independencia.

Algunas menciones relevantes las encontramos en el libro de Anne Staples, La Iglesia en la primera república federal mexicana (1824-1835), no obstante, no profundiza demasiado en el tema..$^{5}$ También Brian Connauhgton toca algu-

\footnotetext{
2 Brian Connaughton, «Clérigos federalistas: ¿fenómeno de afinidad ideológica en la crisis de dos potestades?», en M. MiÑo GRIJALVA, M. TERÁN y otros (coord.), Raíces del federalismo mexicano, Universidad Autónoma de Zacatecas, Secretaria de Educación y Cultura del gobierno de Zacatecas, 2005, pp. 71-88, especialmente las páginas 79-82.

${ }^{3}$ El estado estaba dividido para su administración político-económica en partidos. Hacia 1830, el número de partidos en el estado era de 30 .

${ }^{4}$ Pueden revisarse los siguientes textos: A. Hernández Chávez y M. Terán Fuentes (coords.), Federalismo, ciudadanía y representación en Zacatecas, Zacatecas, Universidad Autónoma de Zacatecas-Consejo Nacional para la Cultura y las Artes, 2010; M. DE VEGA, Los dilemas de la organización autónoma; Zacatecas 1808-1832, México, Colmex, 2005; M. TERÁN, De provincia a entidad federativa: Zacatecas, 1786-1835, Zacatecas, Tribunal Superior de Justicia del estado, 2007; B. RoJAs, edición, La diputación provincial de Zacatecas, actas de las sesiones, 1822-1823, México, Instituto Mora, 2003; Héctor SÁNCHEZ TAGLE, Insurgencia y contrainsurgencia en Zacatecas, 1811-1813, Zacatecas, Tribunal Superior de Justicia, 2008; R. AmARo PeÑAflores, Los gremios acostumbrados. Los artesanos de Zacatecas, 1780-1870, México, Universidad Pedagógica Nacional, 2002; R. Ríos, Formar ciudadanos: sociedad civil y movilización popular en Zacatecas, 1821-1853, México, CESU/Plaza y Valdés, 2005; F. GARCíA GONZÁLEZ, Familia y sociedad en Zacatecas. La vida de un microcosmos minero novohispano, 1750-1830, El Colegio de México/Universidad Autónoma de Zacatecas, México, 2000, entre otros.

${ }^{5}$ A. StAPLes, La iglesia en la primera república federal mexicana (1824-1835), México, Secretaría de Educación Pública, 1976, (SepSetentas, 237).
} 
nas cuestiones en dos de sus obras, aportando importantes datos, ${ }^{6}$ lo mismo que hacen William Taylor y Martha Eugenia García Ugarte; el primero en relación con los curas párrocos y la segunda en cuanto a la política eclesiástica de la primera república federal. ${ }^{7}$ De manera más específica para el caso de Zacatecas, Arturo Burciaga Campos en su libro Las flores y las espinas. Perfiles del clero secular en el noreste de Nueva Galicia (1750-1810), ${ }^{8}$ enfoca precisamente la cuestión de los curatos en las postrimerías de la etapa colonial, por lo que no avanza hacia el periodo posindependiente. Por tanto, de todo esto se desprenden algunas preguntas ¿Cuál era la situación eclesiástica de Zacatecas una vez iniciada la vida independiente? ¿A qué jurisdicción eclesiástica pertenecía? ¿Cuál era la situación de sus parroquias? ¿Por qué pidieron las autoridades a los curas párrocos información sobre ellas? ¿Qué fines tenía tal indagación? ¿Qué resultados finales se obtuvieron?

En este trabajo nos proponemos examinar el expediente elaborado con los informes sobre obvenciones parroquiales de Zacatecas enviados a las autoridades por los curas párrocos de gran parte de la entidad en 1831, con el fin de conocer como estaba organizada la iglesia localmente y qué tipo de problemáticas enfrentaba, sobre todo desde estos ámbitos más bajos, lo que permitirá acercarnos a conocer como se estaban resolviendo las relaciones entre Estado e Iglesia en Zacatecas después de la independencia.

Con ese fin, describiremos a grandes rasgos cuál era la situación de las relaciones entre el Estado y la Iglesia en Zacatecas; enseguida, daremos la descripción y contextualización del documento, señalando también sus limitaciones así como sus posibilidades, pues su factura responde a los conflictos que en esos años trataban de resolverse entre Iglesia y Estado en la mayor parte de México; finalmente, haremos análisis de algunos de los elementos cuyos datos están contenidos en el documento sobre las parroquias.

Básicamente, este trabajo está elaborado a partir del expediente mencionado y con la escasa bibliografía con que se cuenta sobre el tema para el caso de Zacatecas. Consideramos que este primer acercamiento y la reflexión final lograrán abrir un panorama que, más adelante, permita el planteamiento para el caso

${ }^{6}$ También B. Connaghton aborda algunas cuestiones en dos de sus obras, «¿Clérigos federalistas...», op. cit., e Ideología y sociedad en Guadalajara (1788-1853), México, CONACULTA, 1992.

7 W. TAYlor, Ministros de lo sagrado, trad. de Óscar Mazín y Paul Kersey, México, El Colegio de Michoacán, Secretaria de Gobernación, El Colegio de México, 1999. Passim. M. E. GarCía Ugarte, Poder político y religioso. México siglo XIX, México, Cámara de diputados-UNAM-Asociación Mexicana de Promoción y Cultura Social-Instituto Mexicano de Doctrina Social Cristiana, Miguel Ángel Porrúa, 2010, pp. 45-97.

${ }^{8}$ Si bien el periodo que cubre es la segunda mitad del XVIII hasta 1810 y el espacio está más concentrado en las jurisdicciones de Fresnillo y Zacatecas. A. BuRCiAGA CAMPOS, Las flores y las espinas. Perfiles del clero secular en el noreste de Nueva Galicia (1750-1810), Zacatecas, Universidad Autónoma de Zacatecas-Instituto Zacatecano de Cultura, 2006.

Hispania Sacra, LXIII

128, julio-diciembre 2011, 653-679, ISSN: 0018-215-X 
zacatecano de otros problemas relacionados a esta importante temática de la etapa independiente.

\section{LA CUESTIÓN ECLESIÁSTICA EN ZACATECAS}

Durante la guerra de independencia, la participación de clérigos seculares y regulares, adscritos a las filas realistas o insurgentes, fue muy notable en Zacatecas. De tal forma, después de lograda la independencia, esa presencia siguió siendo importante en la política. Los hombres de la iglesia actuaban en los órganos de gobierno de manera muy activa. Sin embargo, las relaciones entre una y otra potestad eran las que estaban en juego, por lo que su solución pronto tuvo que ser atendida. Para comenzar a hablar de la problemática eclesiástica en Zacatecas, recordemos en principio que las dos diócesis de las que dependía -Guadalajara y Durango- estaban, para esos años, y como muchos otros obispados de la República, en sede vacante. Sus titulares, Juan Francisco Castañiza en el primer caso y Juan Ruiz de Cabañas en el segundo, habían dejado sus diócesis en los años posteriores a la creación de la primera república federal. ${ }^{9} \mathrm{La}$ ausencia de esa autoridad dificultaba los quehaceres de la Iglesia, así como el arreglo de los negocios entre ambas potestades, por lo que se empujaba más a que los políticos se animaran a hacer proposiciones en torno a qué hacer en relación con estos asuntos de materia eclesiástica. ${ }^{10}$

De hecho, en la constitución estatal de 1825 se había otorgado el poder al gobernador para proveer las dignidades locales, como fue propuesto también en otros estados, ${ }^{11}$ si bien su autoridad quedaba limitada a eliminar nombres nongratos de las listas a presentar a las autoridades respectivas. También podían entablar relaciones formales con la Iglesia sin la intervención de Roma. De los alcances de tales medidas no tenemos datos por ahora, en cambio, sí que en los años siguientes continuó el esfuerzo por lograr la sujeción del poder eclesiástico al civil.

Prueba de ello fue que, en 1827, el clérigo y diputado zacatecano José Guadalupe Gómez Huerta, presentó ante el Congreso local una serie de propuestas en materia eclesiástica. En principio, aludía al sometimiento que en lo religioso vivía Zacatecas ante la Diócesis de Guadalajara, principalmente por el dinero que iba hacia aquella entidad producto de las obvenciones, diezmos y otros ingresos. En particular, echó en cara que se tuviera que pagar por el servicio al

${ }^{9}$ A. Staples, op. cit., pp. 20-21. Juan Ruíz de Cabañas Crespo dejó vacante su diócesis el 28 de noviembre de 1824; mientras que Juan Francisco Castañiza lo hizo el 29 de octubre de 1825.

10 Sobre la situación en general puede revisarse el primer capítulo de M. E. García UGARTE, op. cit., pp. 45-97.

11 Ibid., pp. 59. 
culto; pedía que asuntos como las dispensas matrimoniales fueran resueltas por sacerdotes locales y no se tuviera que recurrir a Roma, dinero de por medio, para solucionarlas. Sobre todo, proponía que se creara una autoridad religiosa suprema en el estado que hiciera frente a los obispados de Guadalajara y Durango.

Gómez Huerta argumentó la necesidad de suprimir los derechos parroquiales y, en cambio, señalaba que se creara un fondo eclesiástico para costear la labor de los curas. Además, pedía que se suprimieran los diezmos y otros cobros eclesiásticos. Creía además que el Estado debía costear los gastos del culto. Estos y otros planteamientos radicales fueron la tónica de su discurso ante el congreso. ${ }^{12}$ Precisamente en ese año, se tomaron medidas en relación con el cobro de las obvenciones parroquiales en el estado, de lo que se hablará adelante.

Tiempo después, las autoridades zacatecanas solicitaron al conocido clérigo José Miguel Gordoa- ${ }^{13}$ quien por cierto mantenía una actitud beligerante con las autoridades zacatecanas, ${ }^{14}$ que emitiera un juicio sobre la posibilidad de erigir un Obispado en Zacatecas, dado que, como antes se señaló, hasta ese momento la jurisdicción eclesiástica que le correspondía a este estado eran los obispados de Guadalajara y Durango. ${ }^{15}$

La respuesta del clérigo que llegaría a ser nombrado obispo de Guadalajara, fue bastante moderada y en gran parte contraria a la postura asumida por Gómez Huerta; sobre todo, Gordoa se pronunció en contra de la intromisión del poder secular en el eclesiástico, aunque concordaba con la idea de que se hiciera posible dicha erección, siempre y cuando lo realizarán las personas adecuadas y bajo condiciones propicias. No pasó nada con esa petición, más que

\footnotetext{
12 B. Connaughton, «¿Clérigos federalistas...», op. cit., pp. 79-80.

13 José Miguel Gordoa (1777-1832), Diputado por la provincia de Zacatecas, nació en Gran Pino (Real Álamo) el 21 de marzo en 1777. Estudió en el Colegio de San Francisco de Sales de Guanajuato y, luego, Filosofía en Guadalajara, y Teología y Cánones en Méjico, donde llegó a doctorarse. Elegido diputado el día 27 de junio de 1810, se le otorgaron sus poderes el día 29 de agosto, siendo ratificado por las Cortes el día 27 de febrero de 1811, jurando y tomando posesión el día 4 de marzo. Fue nombrado Vicepresidente de las Cortes, y después Presidente de las Cortes Extraordinarias, volviendo a ser diputado, suplente, en las Cortes Ordinarias de 1813. Se le concedió la Cruz de Carlos III y se le nombró medio racionero de la catedral de Méjico, llegando a ser rector del Seminario de Guadalajara. Con la independencia de Méjico fue diputado por la provincia de Zacatecas en el Congreso Constituyente (1823-1824), del que llegó a ser Presidente y uno de los firmantes de la nueva Constitución. En 1824 fue gobernador de la mitra y un año después vicario capitular, siendo nombrado Obispo en 1831. Considerado como un moderado partidario del liberalismo, murió en la Quinta de Camacho, en el barrio de la parroquia de Jesús (Guadalajara) el 12 de julio de 1832, cuando realizaba una visita a la región de Colima, en las playas del Pacífico. http://www.cadiz2012.es/diputados.asp?id=13. Consultado el 16 de julio de 2009.

${ }^{14}$ Sobre el asunto puede verse M. E. García UGARTE, op. cit., cap. 1.

15 B. Connaughton, Ideología y sociedad..., op. cit., pp. 323-325.
} 
causar alboroto entre los involucrados. Temas como este, y otros, estuvieron, pues, en la agenda política de un gobierno como el de Francisco García Salinas en los cuatro años de su gobierno. ${ }^{16}$

En efecto, a principios de 1829, cuando García Salinas asumió su cargo al gobierno de Zacatecas y junto con él arribara al poder un grupo de jóvenes políticos zacatecanos, además de contar con el apoyo de un liberal radical como lo era Valentín Gómez Farías, se tomaron otras medidas para el arreglo de los asuntos eclesiásticos. En principio, a partir de 1830, por decreto del Congreso local del 12 de agosto se dejó fuera de los cargos como legisladores a los clérigos, quienes habían tenido un papel relevante durante la guerra de independencia y en las legislaturas de los primeros años de la república federal; después, en 1831, se clausuró el Colegio de San Luis Gonzaga, de fundación jesuita, y que, en esos momentos, estaba a cargo de los seculares; ${ }^{17}$ también presentó el gobernador el proyecto de creación de un banco, una de cuyas fuentes serían los bienes de la iglesia; 18 y, además, se buscó que, como en otros estados, se adjudicara el gobierno el nombramiento de los titulares de las parroquias, así como el arreglo de asuntos tan espinosos como eran la cuestión de los diezmos y los aranceles parroquiales, parte de lo cual había sido propuesto por el diputado Gómez Huerta. ${ }^{19}$

El cuarto congreso constitucional del estado convocó a un concurso en el que se premiaría con dos mil pesos y una medalla de oro al mejor ensayo o disertación sobre el arreglo de rentas y bienes eclesiásticos. La obra ganadora fue, como es sabido, la de José María Luis Mora, Disertación sobre la naturaleza y aplicación de las rentas y bienes eclesiásticos, y sobre la autoridad a que se hallan sujetos en cuanto a su creación, aumento, subsistencia o supresión. ${ }^{20}$

Todas las acciones anteriores estaban encaminadas, como se observa, al arreglo de las relaciones entre el Estado y la Iglesia. En particular sobresalió el asunto de la creación de una oficina de cobro del diezmo. Debido a que la legislatura de Jalisco cesó en 1827 la jurisdicción sobre este emolumento en los es-

16 M. de VEGA, op. cit., pp. 249-251.

17 Rosalina Ríos ZúÑIGA, «La secularización de la enseñanza en Zacatecas. Del colegio de San Luis Gonzaga al Instituto Literario de Zacatecas, 1786-1838», en Historia Mexicana, 174: 1994, pp. 298-332.

18 Ibid., pp. 267, 271-280.

19 Véase B. Connaughton, Ideología y sociedad..., op. cit., 326-327.

20 J. M. L. MoRA, Disertación sobre la naturaleza y aplicación de las rentas y bienes eclesiásticos, y sobre la autoridad a que se hallan sujetos en cuanto a su creación, aumento, subsistencia o supresión, facsímil, en J. M. L. MoRA, Crédito Público, y otros escritos, advertencia de María del Refugio GonzÁlez, México, Coordinación de Humanidades/UNAM/Miguel Ángel Porrúa, 1986. pp. 169-262. La obra se publicó hasta 1833. Véase también J. M. L. MoRA, Revista política de las diversas administraciones que ha tenido la república mexicana hasta 1837, México/UNAM/Miguel Ángel Porrúa, 1986. 
tados antes comprendidos en la diócesis de Guadalajara, como lo ordenó el decreto núm. 17 del gobierno federal del 16 de febrero de ese año, ${ }^{21}$ el gobierno de Zacatecas comenzó a hacerse cargo de su cobro, como bien lo señala en sus Memorias el gobernador Francisco García Salinas; aunque también consideraba que era necesario, dada la naturaleza de dicho ingreso, que la autoridad eclesiástica volviera a hacerse cargo de ello, siempre y cuando la administración continuara en la capital del estado y se pusiera un contador por parte del gobierno, como lo dijo el propio García Salinas: «y la provisión de los administradores del diezmo se haga por ternas presentadas a la autoridad que designe el Congreso conservándose los derechos que las leyes hubieren dado a los ya establecidos».22

Dos años después se mencionó, también en la Memoria de gobierno, que el legislativo había ya aprobado un nuevo reglamento para el mejor funcionamiento de la oficina de diezmos, a la vez que señalaba los escasos ingresos debido a los bajos precios que habían tenido las semillas en los años a que correspondía la memoria. ${ }^{23}$ Finalmente, la memoria de 1834 no reportó nada concerniente al asunto de los diezmos y no conocemos, por ahora, el fin de este asunto. ${ }^{24}$

En general, puede observarse que el tipo de problemas suscitados en Zacatecas respecto a estos temas seguía la corriente que al respecto se mantenía y estaba resolviéndose en otros lugares del país, es decir, tenía relación con la administración de los bienes de la iglesia, los diezmos, la provisión de parroquias e, incluso, con la todavía importante participación de los sacerdotes en la política. ${ }^{25}$

Así, entre otras medidas tomadas por las autoridades de Zacatecas para resolver o avanzar en la cuestión eclesiástica, estuvo una que quedó asentada en un decreto aprobado por el Congreso local el 30 de junio de 1831, y que fue dada a conocer el 4 de julio. La orden fue enviada a los curas párrocos del territorio estatal por mandato del señor provisor y gobernador de la sagrada mitra de Guadalajara en 18 del mismo. Mediante dicho documento se solicitaba a los responsables de las parroquias del estado la elaboración de un informe que reuniera datos sobre tres puntos, a saber: primero, los ingresos habidos por aranceles parroquiales en sus respectivas localidades; segundo, los egresos pro-

\footnotetext{
${ }^{21}$ M. E. García UGarte, op. cit., p. 81.

22 F. García SAlinas, Memorias presentadas por el C. Francisco García, gobernador del estado de Zacatecas, al congreso del mismo, sobre los actos de su administración en los años de 1829 a 1834. Mandadas reimprimir por el gobernador constitucional Gabriel García Elías, hijo de aquel ciudadano, para obsequiar los pedidos de algunos estados por carecerse absolutamente de ejemplares, Zacatecas, Imprenta de N. de la Riva, 1874. Memoria 1831, pp. 26.

${ }^{23}$ F. García Salinas, op. cit., Memoria, 1833, p. 27.

${ }^{24}$ M. de VeGA, op. cit., pp. 250-251.

${ }^{25}$ Moisés ÓRNELAS, «¿Disciplinar o castigar? Sacerdotes y política en el Obispado de Michoacán (1831-1850), en R. AguiRre y L. EnRíQueZ, coords., La iglesia Hispanoamericana, de la colonia a la república, México, IISUE/UNAM, 2008, pp. 331-352.
}

Hispania Sacra, LXIII

128, julio-diciembre 2011, 653-679, ISSN: 0018-215-X 
ducidos por motivo del culto y, tercero, el cálculo de lo que sería necesario que expendiera el gobierno para el sostenimiento del mismo. Veamos ahora las particularidades del expediente sobre curatos.

\section{EL INFORME DE LOS CURAS Y SU OBJETIVO}

Los curas párrocos eran los representantes de la Iglesia en ciudades, villas y comunidades pequeñas; tenían la función de instruir a sus feligreses y administrarles los sagrados sacramentos, esto es en los bautizos, entierros, misas de cualquier tipo, entre otros, como bien lo ha estudiado William Taylor. Por estos últimos realizaban cobros, llamados también obvenciones o aranceles parroquiales, que eran permitidos por las autoridades eclesiásticas y que aumentaban los ingresos de las parroquias; disfrutaban, asimismo, de la suficiente libertad para «hacer negocios». ${ }^{26}$ De allí el interés de los eclesiásticos por obtener aquellas demarcaciones parroquiales más «jugosas», que no eran tantas, pues eso determinaba el monto de sus ingresos y, por tanto, su jerarquía. ${ }^{27}$ Sin embargo, no se trataba únicamente de una relación monetaria entre la sociedad y la iglesia, pues, como señala Anne Staples,

«Las tarifas impuestas por la iglesia a los feligreses se hicieron tradicionales por fuerza de la costumbre y constituyeron uno de los vínculos y motivos de relación más fuertes entre ambas partes, aunque no por ello dejaron de ser causa de muchos abusos; lo prueba las quejas hechas por los laicos ante las autoridades civiles y eclesiásticas por las cargas excesivas que se vieron obligados a pagar».28

Desde antes de la independencia, el cobro de estos servicios se había hecho de manera bastante irregular y por ello había habido muchas quejas de los feligreses. Los reyes de España habían tratado de regularlos para evitar problemas entre comunidades y curas. En 1767 Carlos III estableció un arancel único para el pago de los derechos parroquiales, pero, como lo indica la legislación que se dictó en 1857 y muchas situaciones particulares, entre esos dos momentos, nunca pudo lograrse la regularización del pago de esos servicios. ${ }^{29}$

Zacatecas no fue la excepción a ese conflicto, y en noviembre de 1827 el gobierno trató de encontrar una solución para que los feligreses pagaran sus dere-

\footnotetext{
26 J. EsCRICHE, Diccionario razonado de legislación y jurisprudencia. Nueva edición revisada y considerablemente aumentada, Madrid, Imprenta de D. Juan O. Cuesta, 1874, vol. II, entrada C.; A. BuRCIAGA CAMPOS, op. cit., p. 152.

27 También W. TAYLOR, op. cit., cap. 6 «Ganarse la vida»., pp. 183-223.

28 A. STAPLES, La iglesia en la primera..., op . cit., p. 130-131. William Taylor, Ibid.

${ }^{29}$ A. STAPLes, op. cit., pp. 127-129. Véase el decreto de 11 de abril de 1857 en torno a los aranceles parroquiales para el cobro de derechos y obvenciones, la llamada Ley Iglesias.
} 
chos parroquiales «sin alterarlos y sin ofender a la iglesia». ${ }^{30}$ Todo sugiere que, sin embargo, nada pasó. Hasta 1831 fue cuando volvió a salir a la mesa de la discusión el asunto de las obvenciones parroquiales, con seguridad no solo en el estado, pues otros asuntos en materia eclesiástica se debatían en el Congreso nacional en ese mismo año. ${ }^{31}$

En el plano local, se buscaba, al parecer, conocer la riqueza que se producía por las obvenciones parroquiales, así como poner en marcha acciones que condujeran a su arreglo, incluso existía la posibilidad de que se tratará de exonerar a los feligreses de su pago y que corriera este a cuenta del estado, como se verá adelante. Veamos ahora las características de este expediente.

El Informe de los curas en el estado de Zacatecas, sobre extensión de sus parroquias, número de habitantes de que éstas se componen y producto de sus emolumentos, es un expediente conformado con 17 informes del mismo número de parroquias, enviado por los curas párrocos a las autoridades de la mitra de Guadalajara y a las civiles en Zacatecas, en 1831.

Cada uno de estos documentos contiene datos básicamente relacionados con las obvenciones parroquiales, por lo mismo se desprende información, como lo dice el título al frente del mismo, relacionada con la extensión de las parroquias, el número de bautismos, casamientos, entierros y gastos del culto que había en cada uno de ellos. Adicionalmente, se pidió a los curas que estimaran lo que se requería para mantener el culto en caso de tenerlo bajo su administración la autoridad civil.

Se trata en muchos sentidos de una información sumamente rica y compleja cuyo contenido sugiere una serie de abordajes en torno a las parroquias en $\mathrm{Za}$ catecas. No obstante, el expediente hallado solamente conserva los datos de 17 de ellas, todas de la jurisdicción de la diócesis de Guadalajara, que fueron enviados por los respectivos clérigos entre julio y septiembre de 1831. En ese mismo sentido, no podemos decir con exactitud las fechas extremas del expediente y del proceso mismo debido a que, como antes se indicó, el documento se encuentra incompleto, pues el número total de parroquias existentes en Zacatecas, por lo que abajo se analiza, era mayor. Así pues, el primer paso a seguir aquí fue establecer el número total de parroquias existentes en el estado, incluyendo las del obispado de Durango así como, incluso, algunas correspondientes también al de Guadalajara y que no fueron reportadas.

De acuerdo con el catálogo de curatos o parroquias de Fernando Navarro y Noriega, publicado en México en 1813,32 había en la provincia de Zacatecas

\footnotetext{
${ }^{30}$ Ibid., p. 133.

${ }^{31}$ Ibid., pp. 63-64.

32 «Catálogo de los curatos que comprende el Reino de Nueva España en cada una de sus diócesis, con expresión de los partidos e intendencias a que están sujetos en lo político (tomado del que publicó 
previo a la independencia, 5 bajo la jurisdicción del obispado de Durango y 20 por lo que toca a Guadalajara. Es decir, sumadas esas cifras, en total existían para 1813, 25 curatos en la intendencia de Zacatecas, que son los incluidos en el cuadro siguiente:

\section{Cuadro 1 \\ Parroquias existentes en la intendencia de Zacatecas pertenecientes a los obispados de Durango y Guadalajara, 1813}

\begin{tabular}{|l|l|}
\hline \multicolumn{1}{|c|}{ Diócesis de Durango } & \multicolumn{1}{c|}{ Diócesis de Guadalajara } \\
\hline 1.- Chalchihuites, Sombrerete & *Aguascalientes (Villa de) \\
\hline 2.- Mezquital (San Juan del), Nieves & Asientos de Ibarra (Real de los Asientos de) \\
\hline 3.- San Miguelito del Mezquital, Nieves & Burgo de San Cosme, Fresnillo \\
\hline 4.- *Nieves (Real de Santa María de las) & *Fresnillo (Villa del) \\
\hline 5.- *Sombrerete (Real de) & Huejucar, Juchipila \\
\hline 6.- & Jalpa, Juchipila \\
\hline 7.- & *Jerez (Villa de) \\
\hline $8 .-$ & *Juchipila \\
\hline 9.- & San José de Gracia, Aguascalientes \\
\hline $10 .-$ & San José de la Isla, Aguascalientes \\
\hline $11 .-$ & *Mazapil \\
\hline $12 .-$ & Mecatabasco \\
\hline $13 .-$ & Mesquital, Juchipila \\
\hline $14 .-$ & Monte Escobedo, Fresnillo \\
\hline $15 .-$ & Nochixtlán, Juchipila \\
\hline $16 .-$ & Ojuelos (hacienda), Sierra de Pinos \\
\hline $17 .-$ & Pánuco (Real de), Zacatecas \\
\hline $18 .-$ & *Sierra de Pinos (Real de) \\
\hline $19 .-$ & Teul, Fresnillo \\
\hline $20 .-$ & Valparaiso, Fresnillo \\
\hline
\end{tabular}

Fuente: Elaborado con base en el catálogo publicado por Fernando Navarro y Noriega, op. cit., pp. 290-296.

* Los lugares señalados con asterisco son capitales de partido.

D. Fernando Navarro y Noriega en Méjico el año de 1813.)», en José María Luis Mora, Crédito Público, op. cit., pp. 374-399. 
Por lo que toca a nuestro expediente, contamos con informe de las siguientes parroquias:

Cuadro 2

Parroquias que aparecen en el expediente de 1831

\begin{tabular}{|c|l|}
\hline Diócesis de Durango & \multicolumn{1}{|c|}{ Diócesis de Guadalajara } \\
\hline $1 .-$ & Aguascalientes \\
\hline $2 .-$ & Asientos \\
\hline $3 .-$ & Jerez \\
\hline $4 .-$ & Juchipila \\
\hline $5 .-$ & Moyahua \\
\hline $6 .-$ & Mesquital del Oro \\
\hline $7 .-$ & Nochixtlán \\
\hline $8 .-$ & San José de Gracia \\
\hline $9 .-$ & San José de la Isla \\
\hline $10 .-$ & San Cosme \\
\hline $11 .-$ & $* *$ Tabasco \\
\hline $12 .-$ & Tepechitlán \\
\hline $13 .-$ & Teul \\
\hline $14 .-$ & Tlaltenango \\
\hline $15 .-$ & Valparaíso \\
\hline $16 .-$ & Villanueva \\
\hline $17 .-$ & Villa de Calvillo \\
\hline $18 .-$ & Zacatecas \\
\hline
\end{tabular}

Formado del Informe de los curas...

** No se incluye en el informe, pero la fuente de donde se tomó indica que el documento fue elaborado a partir del mismo decreto que originó aquellos pertenecientes al expediente que aquí se analiza..$^{33}$

Cómo puede apreciarse, el informe da cuenta de un total de 17 parroquias, todas de la diócesis de Guadalajara, ninguna perteneciente a la de Durango. En el caso de Tabasco, si bien no aparece en el informe, sabemos por otra fuente que el cura envío también su informe ese mismo año. Asimismo, el párroco interino de Salinas recibió la comunicación de las autoridades, pero les contestó señalando su confusión porque las autoridades civiles de San Luis le informa-

${ }^{33}$ Los datos están tomados de un informe hallado en el Obispado de Guadalajara de fecha junio de 1831. Véase http://www.e-local.gob.mx/work/templates/enciclo/zacatecas/municipios/32044a.htm Consultado el 26/06/09

Hispania Sacra, LXIII

128, julio-diciembre 2011, 653-679, ISSN: 0018-215-X 
ron, al momento de tomar posesión de la parroquia, que ese territorio ya pertenecía a San Luis Potosí, aunque haría lo que se le pidiera. Lo más probable es que no se le diera indicación alguna pues no aparece el informe de Salinas. ${ }^{34}$

Así pues, contamos con la certeza de la mención de 18 parroquias adscritas al Obispado de Guadalajara. Por otro lado, existen algunas discrepancias en los números, pues mientras el documento de Fernando Navarro señala la existencia de 20 pertenecientes a la diócesis de Guadalajara, incluyendo las de Ojuelos, Huejucar y Pánuco, éstas no aparecen en el segundo cuadro; por su parte, en el Informe son incluidas otras como Moyahua, Tepechitlán y Tlaltenango, que no aparecían en el primer listado. Todavía más, la de Fresnillo, una de los más grandes e importantes junto con la de Zacatecas -de acuerdo a William Taylor y Arturo Burciaga-, tampoco está incluido en el expediente de 1831.35

Estas discrepancias en las cantidades sugieren que el número de parroquias después de la independencia debió de ser mayor para la entidad en la época, a los veinticinco enunciados por Noriega. Por ejemplo, hasta 1814, Moyahua, que era ayuda de parroquia de Juchipila, pasó a ser curato independiente en este año, y debió haber habido otros casos similares. ${ }^{36}$ Sin duda, tuvo que ver también el cambio en las demarcaciones administrativas civiles que se comenzaron a realizar a partir de $1824^{37}$ y que llevaron a cambios de jurisdicción en el orden eclesiástico, como son los casos enunciados, y que forman parte de la dinámica territorial que prevaleció en esas primeras décadas después de la independencia. Así, aún sin aclarar totalmente este punto, pasemos enseguida a señalar cuál era el objetivo de solicitar dichos informes.

No tenemos por ahora fuentes directas que nos indiquen claramente qué objetivos tenían las autoridades para solicitar los informes. Sin embargo, nos serviremos para ello del propio expediente, pues en algunos de los comentarios

\footnotetext{
${ }^{34}$ Infome de curatos, fs. 36.

35 W. TAYLOR, op. cit., pp. cap. 2, p. 61; Burciaga CAMPOS, op. cit., pp. 84-89. Sin duda, la parroquia de Fresnillo merece un estudio particular, que bien podrá hacerse a partir de los acervos documentales existentes en el Archivo de la Parroquia de la Purificación, en Fresnillo, sin embargo, por ahora hemos tenido que conformarnos con las alusiones sobre su riqueza e importancia, de los autores aquí mencionados.

${ }^{36}$ P. GERHARD, La frontera norte de la Nueva España, trad. de Patricia Escandón Bolaños, México, Universidad Nacional Autónoma de México, 1996. Mapas de Bruce Campbell. pp. 132-133. Tepechitlán pertenecía a la parroquia de Tlaltenango, después también se separó, aunque no sabemos aún cuando ocurrió esto.

${ }^{37}$ La gran extensión del partido de Fresnillo es mencionado por Mariana TeRÁN en su capítulo de libro «Soberanía, ciudadanía y representación en la experiencia confederal: Zacatecas, 1823-1835», en A. HeRnÁNDEZ ChÁveZ y M. TERÁn Fuentes, op. cit., pp. 225-226. La autora señala que comprendía «... el distrito parroquial de Fresnillo, el valle de Valparaiso y San Cosme; por Jerez, su distrito parroquial donde se encontraba el pueblo de Susticacan, los Ayuntamientos de Tepetongo y Monte Escobedo; mientras por Tlaltenango, su distrito parroquial, junto con los municipios de Teul y Tepechitlán». Después de la independencia fue disminuido ese territorio, formándose otros partidos.
} 
vertidos por los curas en sus informes, se pueden reconocer indicios de los objetivos, por ejemplo, en el airado comentario vertido por los curas de Jerez y su ayuda de Tepetongo, se dice:

«Los curas, tememos que [la presentación del informe] sea con el objeto de que se falsifican estos [los datos]. El que aquellos deban decir cuando crean necesario decir sobre las ventajas o inconvenientes de los actuales aranceles, con todo lo demás contenido en los otros artículos del ya referido acuerdo, con las adiciones del Sr. Gómez Farías, nos hace entender que se trata de la abolición de los aranceles parroquiales, reduciéndolos a simples pensionistas del Estado, o sea, restituyendo el proyecto del banco por el que muchos respiran». .38

Existía, por lo que se comenta, temor de este cura a la posibilidad de falsificación de los datos, pero sobre todo a la pretendida supresión que les significaría reducirlos a la calidad de «pensionistas» del Estado y, por tanto, suponía la sujeción de los curas a la autoridad civil. Estaba también a la base de la política económica para hacer posible el proyecto del banco que, como se comentó arriba, era otro de los objetivos del gobierno de García Salinas. En la misma protesta se advertía a los miembros del legislativo, quienes discutieron el acuerdo y entre quienes además de Gómez Farías se encontraba Luis de la Rosa, que se manifiesta en contra de las dos medidas, pues, decía airadamente, «no somos súbditos del Estado, como dijo el diputado Rosas en la discusión del acuerdo y si solo del gobierno Ecco. ${ }^{39}$

En otro de los informes, el del cura de Juchipila, este indicó que se conocía un documento «presentado ante la comisión para la reforma de Aranceles en las parroquias comprendidas en el estado de Jalisco», y que se adherirían a él. ${ }^{40}$

Así pues, con base en esos testimonios, podemos decir que el objetivo de recabar la información obedecía al interés de las autoridades civiles en conocer, por una parte, cuanto producían las obvenciones o aranceles parroquiales, quizá para modificarlas, pero también cuánto dinero le sería necesario al gobierno para mantener el culto, de pasar esa función administrativa a sus manos. Mucho más ambiciosamente, deseaban hacer válido el ejercicio del poder civil sobre el eclesiástico. Ante estas circunstancias, es probable que los curas hayan informado de acuerdo a sus intereses, que eran los de la Iglesia, y no precisamente para ofrecer a las autoridades civiles datos veraces que comprometieran su situación. En ese sentido, las preguntas que surgen son: ¿Cómo se reunió dicha información y que se informó? ¿Cuánta certeza existe en lo declarado o en los datos recabados?

${ }^{38}$ Informe de los curas..., ff. 8-9. El subrayado me pertenece.

${ }^{39}$ Informe de los curas..., ff. 8-9.El subrayado me pertenece.

${ }^{40}$ Informe de los curas..., op. cit., fs. 33v. 
Los informes no mantienen un equilibrio entre ellos en cuanto a su estructura; por el contrario, cada cura notificó de acuerdo a como entendió la petición solicitada y también a la organización administrativa que tenía localmente. Así, algunos, quizá los menos, contestaron de manera muy completa, mientras que otros reconocieron no tener los datos suficientes para cumplir de manera adecuada con la encomienda de las autoridades o bien, debido a la desconfianza que les generó esa encuesta, contestaron estrictamente a lo pedido, dejando en algunos casos al posible lector de esos documentos con la duda sobre la certitud de la información vertida en ellos.

Pese a todas las limitantes que tiene nuestro expediente avancemos en el conocimiento de esa esfera de la realidad zacatecana decimonónica, esto es, las especificidades de las parroquias, su número de población, las cantidades que ingresaban o egresaban por concepto de las obvenciones, el cobro hecho de acuerdo al carácter étnico de los habitantes de determinada población, los aspectos concernientes a los curas párrocos $\mathrm{y}$, finalmente, a partir de ello, comentar la importancia del papel de los curas párrocos.

\section{EL PERFIL DE LAS PARROQUIAS}

Hemos dicho en qué consistía una parroquia y cuántas había aproximadamente en Zacatecas. Se trataba de las demarcaciones territoriales encomendadas a un cura párroco quien se encargaba de administrar los sacramentos a la población allí comprendida, en otras palabras, le tocaba hacerse cargo de las almas de los fieles o feligreses. Comprendían no solamente el servicio de la cabecera parroquial sino también el de las haciendas, ranchos, minerales, pueblitos, así como cofradías de las que podían percibir rentas.

El tamaño de cada parroquia, que no fue reportado por todos, era variable, pues, como antes se indicó, podía existir una muy amplia como la de Zacatecas que, de acuerdo a como fue descrito, se extendía por el oriente cuatro leguas ${ }^{41}$ y colindaba con el de Pánuco: por el poniente tenía 10 leguas y lindaba con Fresnillo y Jerez; por el norte tenía tres leguas y limitaba con Fresnillo, mientras que por el sur tenía cuatro leguas y lo hacía con los de Ojo Caliente y San José de la Ysla. ${ }^{42}$ En cambio, la de Asientos informaba que tenía de oriente a poniente, 14 leguas; de norte a sur, 10 leguas; de norte a sudoeste, 12 leguas, y de sud a noreste, 16 leguas. ${ }^{43}$

\footnotetext{
${ }^{41}$ Aproximadamente $4.9 \mathrm{kms}$.

${ }^{42}$ Informe de los curas..., fs. 49-49v.

43 Ibid., fs. 11.
} 
Tales dimensiones así como la topología de que se tratara, incidían en el número de población que cada una tenía, de allí se desprendía la riqueza e importancia que tuviera. ${ }^{44}$ Veamos, pues, la población como el primer elemento a considerar.

De acuerdo al cuadro 3, elaborado con la información tomada de 18 parroquias, solo 2 tenían una población de más de 20000 habitantes, una era Zacatecas y la otra Aguascalientes; esta segunda sobresalía pues contaba con 35000 «almas». Esa enorme población requería para su atención, de acuerdo a lo notificado, un cura y 10 ministros más. ${ }^{45} 6$ tenían una población de más de 10000 habitantes, siendo Jerez, Tlaltenango, Asientos y Nochixtlán las que sobresalían. Otras 7 oscilaban entre 6000 a 9600, 2 más lo eran con menos de 2500 y una no proporcionó la información exacta, solo señaló que contaba con «un corto número de feligreses».

En el cuadro 3 también es posible observar los ingresos y egresos que por obvenciones reportaron las parroquias. En el primer caso, sumaban los cobros que se hacían por servicios como: bautismos, matrimonios, defunciones, misas de difuntos, cofradías y otros. La forma de calcular no resulta tan clara pues en algunos casos, como Moyahua, se dijo que se trataba de un quinquenio: del primero de enero de 1825 hasta el fin del año 1830.46 Zacatecas y Aguascalientes indicaron lo mismo. En otros, se dice que son cantidades anuales. Así pues, esto hace difícil evaluar de manera pertinente cuanto era lo que ingresaba en cada lugar, aunque es lógico que aquellas parroquias que tuvieran mayor extensión y población fueran los que obtuvieran una cantidad mayor. En este caso, Aguascalientes reportó una cantidad a todas luces exorbitante: ¡ $54,000.00$ pesos! por el quinquenio, mientras Zacatecas indicó apenas 7,395 pesos 1/2 real. Recordemos también que, sin estar en el cuadro, la de Fresnillo era una de los mejores y quizá solo competía con la de Zacatecas. Un buen número de parroquias informó tener ingresos menores a 3,000 pesos, anuales, como puede comprobarse en el cuadro.

El segundo dato que importa analizar es el de los egresos, que también fue solicitado por las autoridades para conocer lo que se sufragaba en cada una de las parroquias por los gastos del culto. En este rubro, volvemos a tener datos incompletos, pues solamente 10 de los informes indican esas cantidades, pero to-

\footnotetext{
${ }^{44}$ En los siglos XVI y XVII se intentó que la extensión de las parroquias se definiera a partir del tamaño de la población indígena. El jurista J. de SOLORZANO Y PEREYRA y la Recopilación de Indias consideraron que 400 tributarios era la cifra apropiada para una parroquia indígena, pero, nos dice Taylor, «cierto clero y algunos feligreses se opusieron enérgicamente a los pocos intentos de parte de los prelados y oficiales reales de efectuarlo». Véase W. TAYLOR, op. cit., p. 119.

45 Informe de los curas..., fs. 40.

${ }^{46}$ Informe de los curas..., fs. 46-47v.
} 


\section{Cuadro 3}

Población, ingreso por obvenciones y egresos anuales

de las parroquias de Zacatecas

\begin{tabular}{|c|c|c|c|}
\hline Curato & Población & $\begin{array}{c}\text { Ingreso por } \\
\text { obvenciones, anual o } \\
\text { quinquenal }\end{array}$ & Egresos anuales \\
\hline 1. Aguascalientes & 35000 & $54,000 *$ & $47,720.6$ \\
\hline 2.-Asientos & $\begin{array}{l}\mathbf{1 2 0 1 9} \text { (obligados a los } \\
\text { preceptos de confe- } \\
\text { sión y comunión) }\end{array}$ & $5,0245 / 8$ & \\
\hline $\begin{array}{l}\text { 3.-Jerez más ayuda de } \\
\text { parroquia de Tepeton- } \\
\text { go }\end{array}$ & 18696 & 6,312 & $3,699.4$ \\
\hline 4.-Juchipila & 6200 & 1,638 & $1,877.61 / 6$ \\
\hline 5.-Moyahua & 6593 & $1,997.7 .6^{*}$ & $1,704.0 .6$ \\
\hline 6.-Mezquital del Oro & $\begin{array}{l}\text { Solo dice que es corto } \\
\text { el núm. De feligreses. }\end{array}$ & 946 & \\
\hline 167.4 de la fábrica & No dice & & \\
\hline 7.-Nochixtlán & $\begin{array}{l}\mathbf{1 3 3 6 5} \\
4269 \text { indios }\end{array}$ & \begin{tabular}{|l|}
580 \\
Más lo de las fincas del \\
Santísimo Sacramento
\end{tabular} & 1,300 \\
\hline 8.-San José de Gracia & 6057 & 800 a 1,000 anuales & \\
\hline 9.-San José de la Ysla & 2487 & 922.6 & \\
\hline 10.-San Cosme & 6265 & $3,465.6$ & \\
\hline 11.-Tabasco & 8645 & No dice & No dice \\
\hline 12.-Tepechitlán & 1676 & 175.18 & 288 pesos $3 / 8$ reales. \\
\hline $\begin{array}{l}\text { 13.-Teúl, incluida la } \\
\text { ayuda de parroquia de } \\
\text { la hacienda la Estan- } \\
\text { zuela }\end{array}$ & 6000 & $1,964.7$ & $1,156.7$ \\
\hline $\begin{array}{l}\text { 14.-Tlaltenango, con- } \\
\text { taba con } 2 \text { ayudas de } \\
\text { parroquia }\end{array}$ & 14492 & 3 a 4,000 & 7,300 \\
\hline 15.-Valparaiso & 11318 & & \\
\hline 16.-Villanueva & 9620 & $4,936.61 / 2$ & $4,733.03 / 4$ \\
\hline 17.-Villa de Calvillo & 10000 & No dice & 5,000 \\
\hline 18.-Zacatecas & 20000 & 7,395 p. $1 / 2$ real* & $3,732.5$ \\
\hline
\end{tabular}

Formado de los datos del Informe de los curas....

En negritas van marcadas las cantidades mayores.

Llevan asterisco * los que indicaron reporte quinquenal. 
dos hacen la anotación de que se trata de egresos anuales. Cabe hacer notar que aquellos que reportan las cantidades menores son Tepechitlán, Juchipila, Moyahua y Teúl. En el otro extremo estaban las parroquias más ricas y, por ende, las más apetecidas por los clérigos, como eran las de Zacatecas, Aguascalientes, Jerez y Tlaltenango, sin olvidar, nuevamente, que no se reportó en el informe a Fresnillo.

En todo caso, resulta evidente que hay una correspondencia entre población y producto por obvenciones aunque, obviamente, habría que comparar esas cifras con el total de población reportada por cada parroquia para hacer una mejor interpretación de esas cifras, así como tomar en cuenta las condiciones materiales del territorio que comprendía la parroquia, pues de esto dependía en mucho su riqueza. ${ }^{47} \mathrm{El}$ mayor egreso por gastos de culto también está sugiriendo la necesidad de mayor atención a la población por más cantidad de celebraciones y, por tanto, que habría que tener más ministros, como fue el caso de Aguascalientes.

Otro elemento que arrojan los informes tiene que ver con los montos de cobro según la calidad étnica, dato que también nos permite evaluar la persistencia, después de una década, en el uso o no de ciertas categorías o calidades étnicas, utilizadas durante la etapa novohispana y que no habían quedado atrás. Nos referimos a la distinción de los individuos como peninsulares, criollos, indios, castas, etc., sobre todo considerando que, en términos jurídicos, después de la independencia todos serían llamados y tratados como ciudadanos. De acuerdo con los datos del informe, en muchos lugares de Zacatecas el cargo por los servicios eclesiásticos se hacía todavía considerando las categorías anteriores de indios y españoles y, en algunos casos, de castas.

Así, se especificaba que el cobro de los aranceles parroquiales podía ser de primera y segunda clase; en el primer caso era aplicado a los españoles y, en el segundo, a los indígenas, a quienes, debido a ello, se les reducía el estipendio. En el cuadro 4 puede observarse que en la mayoría de parroquias reportadas se cobraba haciendo la distinción entre indio o español. En otras, muy pocas, como Mesquital del Oro se indicó que se cobraba «a todos como ciudadanos», de acuerdo al Arancel de minas. En Asientos de Ibarra, sin ser tan específica la indicación, se decía que se hacía de acuerdo con dicho Arancel. En otras, como en Villanueva, se reporta que se realizaba el cobro con base en la calidad de españoles, mientras que, en Zacatecas, lo era por la tarifa de castas. Un ejemplo más que importa mencionar es el de Aguascalientes, de la que se indicó se cobraba con el arancel que comenzó a regir en $1815,{ }^{48}$ lo cual nos lleva a complejizar el tema de su desarrollo. En general, puede notarse con facilidad que,

${ }^{47}$ Véase W. TAYLOR, op. cit., cap. 2, pp. 60-67.

${ }^{48}$ Informe de los curas..., fs. 44v.

Hispania Sacra, LXIII

128, julio-diciembre 2011, 653-679, ISSN: 0018-215-X 
ciertamente, no había ninguna uniformidad en el cobro de los aranceles parroquiales para esta época.

Por otro lado, habría que tener otros datos que pudieran indicarnos las cantidades cobradas en cada caso que nos llevaran a comprender la significación de todo esto en términos no solo económicos sino sociales. Anne Staples vuelve a darnos algunos datos importantes al respecto, pues indica que, de acuerdo al nuevo arancel diseñado por el arzobispo Lorenzana en 1767 y que permaneció vigente hasta el fin de la etapa colonial, debían pagar españoles, mestizos, mulatos e indios. Los españoles estaban obligados a pagar un peso por el bautismo, más dos reales a los sacristanes participantes en el acto. Cabe recordar que un peso se dividía en 8 reales. Quienes se casaran pagarían sólo si no pertenecían a la parroquia y esto equivalía a soltar cuatro pesos al sacerdote que oficiara la boda; si había algún adorno extra o música, o alguna otra suntuosidad llegaba a sumar la ceremonia hasta 12 pesos. El costo de los entierros también dependía de la pompa con que se celebraran y podía ser entre 5 hasta 17 pesos.

Los mestizos y mulatos tenían un arancel distinto, pero en cuanto a bautismos les correspondía pagar lo mismo que los españoles; y operaba la misma dinámica que para los peninsulares en el caso de los matrimonios. Por su parte, los indios no debían pagar más de cuatro reales por un bautismo, 6 por la velación, más una cantidad mínima por las amonestaciones y otros actos relacionados con el matrimonio. Los entierros de adultos costaban 3 pesos y los de niños 2 . En cuanto a las cofradías y hermandades, ${ }^{49}$ éstas pagaban cuotas fijas por las misas que solicitaban e igual tocaba a los pueblos en las fiestas de sus santos patronos. Como se dijo arriba, dichos cobros variaban de región a región. Así pues, importaba mucho a los curas párrocos cuánto era el monto de los ingresos por obvenciones, pues esto aseguraba una buena manutención para ellos y su familia.

Ahora bien, es claro que no contamos con los datos del monto de los aranceles para Zacatecas, sin embargo, la baja cantidad de ingresos motivó a que algunos curas se quejaran en los informes por el bajo producto que percibían bajo este rubro, que además no se acompañaba por los correspondientes apoyos en otros ingresos como podían ser los generados por la existencia de cofradías, réditos por rentas de casas, haciendas u otros. A su vez, un cura como el de Aguascalientes expresaba que el arancel «según su estatuto actual lejos de ser gravoso al pueblo en lo general, está expuesto en términos equitativos», por tanto, aseguraba que no correspondía a ninguna contribución civil y que tampoco contribuía «a enriquecer al clero, antes solo se le da una moderada subsisten-

\footnotetext{
${ }^{49}$ Las cofradías como agrupaciones seculares que «agrupaban a un determinado número de fieles y que tenían la finalidad de afianzar el catolicismo y de brindar asistencia material y espiritual a sus miembros, principalmente a la hora de la muerte. Se dividían en terceras órdenes, hermandades, devociones, cuadrillas y cofradías propiamente dichas». A. BURCIAGA CAMPOS, op. cit., pp. 157-158.
} 
cia»..$^{50}$ No obstante, como también ya se mencionó arriba, llegó a haber quejas de la feligresía por los abusos que llegaban a padecer por parte de los curas, que podían tomarse la atribución de no celebrar un casamiento o un entierro si las personas no tenían el dinero suficiente para pagarles por sus servicios.

\section{Cuadro 4 \\ Jerarquías étnicas utilizadas para el cobro de las obvenciones parroquiales en Zacatecas}

\begin{tabular}{|c|c|c|c|}
\hline Curato & $\begin{array}{l}\text { Cobro de obvenciones } \\
\text { sin distinción de } \\
\text { jerarquías étnicas }\end{array}$ & $\begin{array}{c}\text { Cobro de obvenciones a } \\
\text { indígenas }\end{array}$ & $\begin{array}{c}\text { Cobro de obvenciones a } \\
\text { españoles }\end{array}$ \\
\hline Aguascalientes & $\begin{array}{l}\text { se indica se cobraba } \\
\text { con el arancel que co- } \\
\text { menzó a regir en el } \\
\text { año de } 815 \text {. }\end{array}$ & $\mathrm{X}$ & $X$ \\
\hline Asientos & & $\begin{array}{l}\text { Dice cobrar de acuer- } \\
\text { do al arancel de mi- } \\
\text { nas, con las califica- } \\
\text { ciones que en él se ha- } \\
\text { cen* }\end{array}$ & \\
\hline \multicolumn{4}{|l|}{ Jerez } \\
\hline Juchipila & & $\mathrm{X}$ & $\mathrm{X}$ \\
\hline Mesquital del Oro & $\begin{array}{l}\text { Se cobra a todos como } \\
\text { ciudadanos, de acuer- } \\
\text { do con el arancel de } \\
\text { minas? }\end{array}$ & $\begin{array}{l}\text { Dice que carece de } \\
\text { vecinos a los que se } \\
\text { les llama indios... }\end{array}$ & \\
\hline Moyahua & & $\mathrm{X}$ & $X$ \\
\hline Nochixtlán & & $\mathrm{X}$ & $X$ \\
\hline San José de Gracia & & $\mathrm{X}$ & $\mathrm{X}$ \\
\hline San José de la Isla & & $\begin{array}{l}\text { X Los 1lama «hijos } \\
\text { del pueblo» }\end{array}$ & $\mathrm{X}$ \\
\hline San Cosme & & $\begin{array}{l}\mathrm{X} \text { dice que solo se } \\
\text { hace la distinción en- } \\
\text { tre españoles y castas }\end{array}$ & $X$ \\
\hline Tabasco & No hay información & & \\
\hline Tepechitlán & $\mathrm{X}$ & & \\
\hline Teul & & $\mathrm{X}$ & $X$ \\
\hline Tlaltenango & & $X$ & $X$ \\
\hline
\end{tabular}

50 Idem.

Hispania Sacra, LXIII

128, julio-diciembre 2011, 653-679, ISSN: 0018-215-X 
Cuadro 4 (continuación)

\begin{tabular}{|c|c|c|c|}
\hline Curato & $\begin{array}{l}\text { Cobro de obvenciones } \\
\text { sin distinción de } \\
\text { jerarquías étnicas }\end{array}$ & $\begin{array}{c}\text { Cobro de obvenciones a } \\
\text { indígenas }\end{array}$ & $\begin{array}{c}\text { Cobro de obvenciones a } \\
\text { españoles }\end{array}$ \\
\hline Valparaíso & $\begin{array}{l}\text { X Dice haberse hecho } \\
\text { distinción solo en los } \\
\text { matrimonios }\end{array}$ & & \\
\hline Villanueva & $\begin{array}{l}\text { X se cobra a todos por } \\
\text { la tarifa de españoles }\end{array}$ & & \\
\hline Villa de Calvillo & & $\mathrm{X}$ & $\mathrm{X}$ \\
\hline Zacatecas & & $\begin{array}{l}\text { X } \\
\text { Se dice que el cobro } \\
\text { se hace por la tarifa de } \\
\text { castas }\end{array}$ & $X$ \\
\hline
\end{tabular}

Fuente: formado del Informe de los curas...

* Se refiere al Arancel para reales de minas del obispado de Guadalajara de 9 de octubre de 1809.

En cuanto a las cantidades que serían necesarias para sostener el culto en cada uno de las parroquias, en este asunto, como en otros, no todos los curas enviaron tal información, pero podemos asomarnos a revisar algunos ejemplos. El cura de Aguascalientes, señaló que el curato necesitaba ser dotado con 4,000 pesos anuales para el culto y administración. Agregaba que para los 35000 feligreses que atendía por lo menos hacía falta que hubiera 1 cura por cada 1000 almas, pero reculó y opinó que con 1 cura y 10 ministros, dotándolos con 35 pesos, sería suficiente. En el caso de Mesquital del Oro, el eclesiástico indicó que con 1,500 pesos anuales de dotación a la parroquia sería suficiente para su subsistencia, más 500 que servirían para gastos del culto. El de San José de Gracia solicitaba 3,474 pesos anuales, que se distribuirían de la siguiente forma: 2,000 para el cura y 720 para el pago de 2 ministros, correspondiendo 360 [sic] pesos a cada uno..$^{51} \mathrm{El}$ de Tepechitlán calculó que serían suficientes 4,163 pesos anuales, para cubrir los tres rubros. Otro, como el de Villanueva, indicó que bastaba con la misma cantidad que reportaba en su informe: 5,373.2 pesos. Un último caso que merece la pena mencionarse, por lo que nos enseña de la existencia cotidiana de estos sujetos, es el del cura de Villa de Calvillo, quien necesitaba para la manutención suya y «de toda su familia», 2,000 pesos anuales. Esa familia se componía, según su relato, de «su madre, una hermana doncella, la viuda y dos hijos de su hermano finado Julián Orellana, la viuda e hijos de mi hermano Trinidad, y la viuda e hijos de su hermano Jerónimo Aldaco».52 ¡Una familia extensa sin duda muy numerosa! En general, como puede adver-

\footnotetext{
${ }^{51} \mathrm{Idem}$, fs. 22v.
}

52 Idem, fs. 28. 
tirse, los requerimientos para sostener el culto, a los curas y ministros, variaba mucho de un lugar a otro, y servían, básicamente para la subsistencia de éstos.

\section{Cuadro 5}

Montos necesarios para sostener el culto en las parroquias

\begin{tabular}{|l|l|}
\hline Parroquias & Monto necesario para sostener el culto \\
\hline Aguascalientes & 4,000 anuales V 350 para 10 ministros. \\
\hline Mesquital del Oro & 1,500 anuales V 500 para el culto \\
\hline San José de Gracia & 3,474 anuales: 2,000 para el cura y 360 x dos ministros \\
\hline Tepechitlán & 4,163 anuales \\
\hline Villanueva & $5,373.2$ anuales \\
\hline Villa de Calvillo & $\begin{array}{l}\text { 2,000 anuales para el cura y } 50 \text { pesos para cada ministro, aunque } \\
\text { no especifica cuantos son. }\end{array}$ \\
\hline Zacatecas & 8,300 pesos anuales curas y ministros; 5231.3 gastos del culto. \\
\hline
\end{tabular}

Fuente: Informe de los curas...

Finalmente, un quinto elemento que emerge de los informes tiene que ver con quienes ejercían el ministerio, es decir, los curas. Existían varias categorías de curas párrocos diocesanos, como los define Taylor, unas eran formales y otras informales: «Entre las primeras las principales eran la del cura beneficiado, cura interino (cura ad ínterin), vicario y coadjutor». ${ }^{33}$ Los beneficiados, titulares o propios, propietarios del curato, ocupaban el cargo vitaliciamente y tenían el derecho a devengar los ingresos parroquiales junto con trabajo o algún otro beneficio sancionado por la ley o la costumbre. En sus ausencias, podían nombrar curas coadjutores o interinos. Esas separaciones del cargo tenían por origen factores, como enfermedad, periodo de descanso o simplemente porque al titular no le agradaba ese determinado curato «... donde reinaba el yermo de la desolación y la pobreza». ${ }^{44}$ Recordemos que uno de los atractivos que tenía la obtención de un beneficio de este tipo consistía en la abundancia económica que pudiera proporcionar al cura la parroquia. ${ }^{55}$

Además del titular o interino que estuviera a cargo temporalmente de la parroquia, podían contar con un determinado número de ministros que auxiliaban al cumplimiento de la atención a la feligresía, esto dependiendo de la extensión del territorio parroquial. Como ocurría en el caso de Aguascalientes, donde fue-

${ }^{53}$ W. TAYLOR, op. cit., pp. 115-116.

${ }^{54}$ A. Burciaga Campos, op. cit., p. 152.

55 Véase también W. TAYLOR, op. cit., cap. 5 y 6, pp. 147-223. 
ron requeridos por el cura 10 ministros más. Se les conocía como vicarios o coadjutores, o ayudantes o tenientes y la característica más importante que tenían es que no eran beneficiados del cura. De acuerdo con Taylor, su obligación era «relevar al cura de parte o de todas sus obligaciones pastorales, para hacer y trabajar todo lo que no pueden hacer los curas». ${ }^{56}$ Generalmente, en parroquias muy extensas y prósperas, ellos eran los que acudían a los parajes más remotos para ocuparse de los servicios a las comunidades.

En cuanto al acceso al cargo de cura párroco beneficiado, este podía ser por designación del obispo o por concurso. Se realizaba una vez que el candidato hubiera concluido los estudios necesarios, ya fuera en algún colegio o seminario conciliar y recibido el grado correspondiente de bachiller. ${ }^{57}$ Las relaciones familiares podían ser importantes para obtener un mejor beneficio, pero sin duda, las que hubiera entablado con el prelado le garantizaría un mejor destino e, incluso, la posibilidad de ascensos posteriormente, gracia reservada usualmente a quienes ocupaban aquellas que eran más ricas. ${ }^{58}$

En los años de que nos ocupamos, como se ha dicho, no había obispos en las sedes de las que dependían las parroquias de Zacatecas. Quién podía nombrarlos y cómo se procedía, era muy impreciso, por lo menos hasta 1831, cuando bajo el gobierno de Ignacio Bustamante, se aprobó por el Congreso general un proyecto que buscaba resolver el asunto en el plano nacional. Por el mismo, los obispos, en el caso de que los hubiera, o los cabildos eclesiásticos, «debían nombrar a los canónigos, a los prebendados y a otras dignidades. Los gobernadores de los estados en los que en que se hicieran los nombramientos tenían el derecho de rechazar a los individuos mencionados en las listas de candidatos». ${ }^{59}$ En su caso, el presidente lo haría con la catedral metropolitana.

A partir de ahí comenzaron a hacerse nombramientos en algunos estados. Unos meses después, en noviembre de ese mismo año, Bustamante promulgó

\footnotetext{
56 TAYLOR, op. cit., p. 116.

57 Para seguir con puntualidad los requerimientos necesarios para acceder a esos cargos véase R. Aguirre Salvador, El mérito y la estrategia. Clérigos, juristas y médicos en la Nueva España, México, Universidad Nacional Autónoma de México-Centro de Estudios sobre la Universidad, 2002. También W. TAYLOR, op. cit., cap. 4, pp. 123-145. Sin duda, en el caso de Zacatecas quienes alcanzaban alguna prebenda parroquial fueron individuos formados hasta 1831 tanto en el Colegio de San Luis Gonzaga como en Guadalajara. En San Luis Gonzaga la cátedra de teología fue prácticamente la única que se ofrecía, junto con la filosofía, pero en los primeros años de la república los estudiantes interesados en cursarla prácticamente desaparecieron hasta que no hubo manera de continuar abriéndola por falta de ellos; después, instalado la Casa de Estudios de Jerez en 1832 y, posteriormente, el Instituto Literario, en 1837, no apareció esa formación en el curriculum. Véase R. Ríos ZúÑ̃GA, La educación de la colonia a la república. El colegio de San Luis Gonzaga y el Instituto Literario de Zacatecas, 17541854, México, CESU-Ayuntamiento de Zacatecas, 2002, pp. 159 y 165.

58 A. Burciaga CAMpos, op . cit., pp. 205-206.

${ }^{59}$ A. STAPLES, op. cit., p. 64.
} 
otro decreto solicitando que se diera cumplimiento al de 16 de mayo pasado, pues, de lo contrario, el gobernador perdería el derecho de veto sobre los candidatos. Esta problemática tomaría otros cauces más adelante, pero es asunto en el que no profundizaremos. ${ }^{60}$ Veamos ahora la información que tenemos.

El cuadro cinco nos indica que las 18 parroquias de que tenemos información estaban ocupadas, así fuera por interinos. Un dato más, de la Memoria de gobierno de este año nos señala que había en total 32 curas asignados a los diferentes tipos de población, si bien no eran estos los únicos clérigos en el estado, ${ }^{61}$ ni tampoco los que cubrían el total de parroquias.

En cuanto a los que tenemos consignados en nuestro documento, sucedía lo siguiente. El número total de curas del que se tiene referencia a partir del documento es de 19, aunque nuevamente excedemos el número de informes reportados (17), porque aquí incluimos un nombre más, el del cura de la parroquia de Sombrerete que, como antes se dijo, pertenecía a la Diócesis de Durango, no a la de Guadalajara. Tomando en cuenta tal salvedad, tenemos que, en total son 20 curas, pues en el caso de dos lugares, Asientos de Ibarra y Tlaltenango, se reportan dos ministros en cada caso. De ese total, 8 eran interinos, uno se nombró titular y el resto no dijo algo específico sobre su situación.

En cuanto a los interinos, categoría que parece ser situación muy común en esos momentos, algunos curas indican que ellos estaban sustituyendo a los titulares quienes por diversos motivos dejaron sus parroquias. Por ejemplo, fue el caso del cura de Nochixtlán, José Antonio de Velasco Camarena, pagado por el propio titular quien era español y fue separado del cargo a consecuencia del decreto de expulsión de españoles. O el de Juan José Orellana, quien sustituía al titular, un español quien cayó en la «locura» o «enfermedad». Cualquiera que hubiera sido el caso, lo peculiar es que hasta ese momento no habían ni podían ser convenientemente cubiertos las parroquias con titulares, que comenzarían a llenarse a partir de 1831 .

Otro tipo de información también resulta relevante, aunque no la tenemos para todos los casos. Por ejemplo, sabemos que, el cura interino a cargo de la parroquia de Zacatecas, José Ramón Jiménez, fue también el último rector del Colegio de San Luis Gonzaga de esa ciudad; establecimiento que, aún cuando ya en ruinas, fue cerrado precisamente ese año de 1831 por las autoridades del estado. ${ }^{62}$

${ }^{60}$ Véase M. E. García UGarte, op. cit., cap. 1.

${ }^{61}$ F. GARCía SALINAS, op. cit., Memoria 1831, estado núm. 4. «Plan que manifiesta el censo general del estado libre de los Zacatecas con respecto a su población, número de haciendas de campo, ranchos anexos e independientes de ellas: curas, vicarios, clérigos, regulares y casas de beneficiencia [sic]».

${ }^{62}$ Detalles sobre el Colegio de San Luis Gonzaga pueden verse en Rosalina Ríos ZúNIIGA, «La secularización de la enseñanza en Zacatecas. Del Colegio de San Luis Gonzaga al Instituto Literario (1786-1838)», en Historia Mexicana, 174: 1994, pp. 298-332 y en R. Ríos ZúÑIGA, La educación de la colonia..., op. cit. 
Tampoco sobra recordar que, como en muchos otros lugares, los curas de Zacatecas tenían un papel de suma importancia entre la población de las diferentes parroquias o comunidades, siendo quizá líderes naturales a los que se les guardaba obediencia por la mayoría de la población. Recuérdese tan solo que, en 1829, durante los motines de Sombrerete, a Francisco Rivas, cura del lugar, se le encomendó la tarea de calmar los ánimos de la población sublevada, la que después de los oficios del clérigo, retornó a la calma. Situaciones similares, en las que los curas del lugar tenían todavía un lugar muy importante dentro de las poblaciones, se pueden mencionar para distintos lugares del país, como sucedía también en Michoacán e incluso la ciudad de México, por ejemplo. ${ }^{63}$

\section{Cuadro 6 \\ Situación de adscripción de los curas a las parroquias del estado de Zacatecas}

\begin{tabular}{|l|l|l|}
\hline \multicolumn{1}{|c|}{ Curato } & \multicolumn{1}{|c|}{ Nombre del cura } & \multicolumn{1}{c|}{ Situación } \\
\hline 1.-Aguascalientes & Ygnacio Lomas & Interino \\
\hline 2.-Asientos de Ibarra & $\begin{array}{l}\text { José María Plascencia } \\
\text { Casiano de Espinoza }\end{array}$ & No dice \\
\hline 3.-Jeréz & Mariano y Lupinasa & No dice \\
\hline 4.-Juchipila & Mariano Villaseñor & No dice \\
\hline 5.-Mayahua & José de Jesús Fregoso & No dice \\
\hline 6.-Mesquital & Brigido Lezama & Actual encargado del curato \\
\hline 7.-Nochixtlán & $\begin{array}{l}\text { José Antonio de Velasco } \\
\text { Camarena }\end{array}$ & $\begin{array}{l}\text { Pagado por el cura propio debido a su } \\
\text { separación del cargo por español. }\end{array}$ \\
\hline 8.-San Cosme & Antonio Serrano & Interino. Ante notario \\
\hline 9.-San José de Gracia & Juan José Cabrera & No dice \\
\hline 10.-San José de la Ysla & Juan Felipe Arriaga & No dice \\
\hline
\end{tabular}

63 Para el caso de Michoacán véase Moisés ORnElas HernándeZ, «El cabildo eclesiástico en sede vacante y los conflictos locales con el poder civil: el obispado de Michoacán, 1821-1831», en F. J. Cervantes Bello y otros, Poder civil y catolicismo en México, siglos XVI al XIX, México, Benemérita Universidad Autónoma de Puebla/Universidad Nacional Autónoma de México, 2008, pp. 401-425; en el de la ciudad de México, S. PÉrez Toledo, «Movilización social y poder político en la ciudad de México en la década de 1830», en B. Connaughton (coord.), Prácticas populares, cultura política y poder en México, siglo XIX, México, Juan Pablos/Univesidad Autónoma Metropolitana, 2008, pp. 335367. De forma más general, Taylor refiere el papel que jugaban en esas comunidades los curas párrocos. Véase W. TAYLOR, op. cit., cap. 8, pp. 267-311. 
Cuadro 6 (continuación)

\begin{tabular}{|l|l|l|}
\hline \multicolumn{1}{|c|}{ Curato } & \multicolumn{1}{|c|}{ Nombre del cura } & \multicolumn{1}{c|}{ Situación } \\
\hline 11.-Sombrerete64 & Mariano Rivas & Titular \\
\hline 12.-Tepechitlán & José Guadalupe Gómez & No dice \\
\hline 13.-Teul & Eulogio Guzmán & Por ausencia del sr. Cura Interino \\
\hline 14.-Tlaltenango & $\begin{array}{l}\text { Diego Aranda } \\
\text { Juan Hernández Vélez }\end{array}$ & No dice \\
\hline 15.-Valparaiso & Juan José Orellana & $\begin{array}{l}\text { Por enfermedad del presbítero español } \\
\text { Dn. José Manuel de Crespo, cura propio. }\end{array}$ \\
\hline 16.-Villa de Calvillo & José Mariano de Naval & No dice \\
\hline 17.-Villanueva & Felipe Córdova & Por ausencia del Sr. cura propio. \\
\hline 18.-Zacatecas & José Ramón Jiménez & Cura interino \\
\hline
\end{tabular}

Fuente: Formado del Informe de los curas...

\section{UNAS BREVES CONCLUSIONES}

El Informe sobre los curas del estado de Zacatecas... remitido a las autoridades en 1831, contiene una información sumamente valiosa que nos permitió avanzar en tres direcciones: la primera, mediante su necesaria contextualización, nos llevó a adentrarnos a la caracterización de la problemática que en torno a las relaciones Iglesia y Estado se estaban tratando de resolver en Zacatecas y en el México de la república federal. En particular, para ese año, había aspectos que comenzaban a complicarse dado el interés e intención de parte de los políticos zacatecanos por resolver la cuestión eclesiástica de manera favorable a la autoridad civil. Entre los asuntos álgidos que pronto se revolvieron estaban, por ejemplo, la participación o no de clérigos en las actividades políticas, la creación de un banco que tomaría como base bienes de la iglesia, el asunto de las obvenciones parroquiales y los diezmos, entre otros, que se agravaban por la falta de reconocimiento de la Santa Sede de la independencia de México y, por ende, la ausencia del poder de los obispos en sedes vacantes.

\footnotetext{
${ }^{64}$ La información sobre el cura de Sombrerete no forma parte del documento que sirve de base al presente trabajo. Sobre dicho cura, puede seguirse la historia de su intervención en los motines de Sombrerete en Rosalina Ríos ZúÑIgA, «Popular Uprising and Political Culture in Zacatecas: The Sombrerete Uprisings (1829)», Hispanic American Historical Review. 87 (3), 499-536.

65 También fue durante mucho tiempo rector del Colegio de San Luis Gonzaga.
} 
En el caso de la segunda, por el tipo de información que contiene el expediente, nos permitió un acercamiento mucho más certero a la vida y condiciones de las parroquias de Zacatecas y sus problemas, pues ofrece datos de cuántas eran, cuál era su demarcación, quiénes las tenían a su cargo en esos momentos, cuáles eran sus ingresos y egresos, cuánto necesitaban para sostener el culto, entre otros asuntos.

En la tercera, nos sugirió avanzar en la traza de un mapa social por la información que contiene sobre la población, indicando como estaba distribuida, cuánta de ella era indígena, mestiza o española; la riqueza del estado y sus demarcaciones administrativas -en este caso las eclesiásticas, que no siempre correspondían con las civiles-, y el status que guardaban los sujetos nuevos de un estado independiente y moderno.

Ninguna de estas dos últimas direcciones han sido desarrolladas del todo en el presente trabajo, pues, en general, los datos proporcionados por la documentación son valiosísimos, pero responden solo a una parte de la realidad eclesiástica del estado, faltando aquella que toca a la diócesis de Durango, por lo que todavía habría que buscar en los archivos correspondientes la información relacionada con esa otra parte del territorio zacatecano. Finalmente, no sobra decir que otra dimensión que faltó explotar con más detalle y que sin duda es central a la función de los curatos es la económica. El camino, pues, queda abierto para futuras investigaciones. 